\title{
Perancangan Fasilitas Kerja pada Stasiun Kerja Finishing dengan Metode Quality Exposure Checklist (QEC) di CV X Divisi Sarung Tenun
}

\author{
Irsyad Ali Syahid*, Puti Renosori \\ Prodi Teknik Industri, Fakultas Teknik, Universitas Islam Bandung, \\ Indonesia.
}

*irsyad168@gmail.com, putirenosori@yahoo.co.id

\begin{abstract}
CV. X is a textile company that manufactures sarong, napkin rags and other fabric materials. The core production process is carried out by the company with several process elements carried out by the company's business partners (subcontract). The fabrication process of a sarong product is carried out with a semi-automatic machine that is operated by an operator with some process elements that are carried out by a conventional operator. Based on the identification of work risks using the Quick Exposure Checklist (QEC) questionnaire, that operator works in a limited body posture condition so as to produce a score of more than $50 \%$ and the need for action in the near future. These results indicate how high this risks experienced by finishing work station operators. The condition of the operator working in a folded or squatting sitting position, forearm reach, dynamic hand movements plus limited operator motion because sitting without proper facilities is a major problem. If this is not treated as soon as possible it can have a negative impact on the operator such as physical fatigue, decreased operator performance to skeletal muscle injury (mosquletal disorder). Quick Exposure Checklist show that the occupational risk level of work is at level 3 (three) which shown a high score level that action is needed as soon as possible to minimize the risk of work. The proposed action to minimize the risk is to design an ergonomic work facility in accordance with the needs of the operator at the finishing work station using the Anthropometry method.
\end{abstract}

Keywords: Quick Exposre Checklist (QEC), Anthropometry, Facility design.

Abstrak. CV. X merupakan perusahaan tekstil yang memproduksi kain sarung, lap serbet serta bahan kain lainnya. Proses produksi inti dilakukan oleh perusahaan dengan beberapa elemen proses yang dilakukan oleh mitra usaha perusahaan (subcont). Proses pabrikasi produk kain sarung dikerjakan dengan mesin-mesin semi otomatis yang dioperasikan operator dengan beberapa elemen proses yang dikerjakan operator secara konvensional. Berdasarkan identifikasi dan observasi resiko kerja menggunakan kuesioner Quick Exposure Checklist (QEC), operator bekerja pada kondisi postur tubuh yang terbatas sehingga menghasilkan hasil skor lebih dari $50 \%$ dan diperlukannya tindakan dalam waktu dekat. Hasil ini menunjukan besarnya resiko kerja yang dialami operator stasiun kerja finishing. Kondisi operator yang bekerja pada posisi duduk terlipat maupun jongkok, jangkauan tangan kedepan, pergerakan tangan yang dinamis ditambah terbatasnya gerak operator karena duduk tanpa ditunjang fasilitas yang layak menjadi faktor masalah utama. Jika hal ini tidak ditangani sesegera mungkin dapat mengakibatkan dampak negatif terhadap operator seperti kelelahan fisik, penurunan kinerja operator hingga cedera otot rangka (mosquletal disorder). Hasil penilaian resiko kerja Quick Exposure Checklist menunjukkan bahwa level resiko kerja pekerjaan berada pada level 3 (tiga) yang menunjukan level skor tinggi sehingga perlu dilakukannya tindakan dalam waktu dekat guna meminimasi besarnya resiko kerja. Tindakan yang diusulkan guna meminimasi resiko tersebut yaitu dengan merancang fasilitas kerja yang ergonomis sesuai dengan kebutuhan operator pada stasiun kerja finishing dengan menggunakan metode Antropometri.

Kata Kunci: Quick Exposure Checklist (QEC), Antropometri, Perancangan fasilitas. 


\section{A. Pendahuluan}

$\mathrm{X}$ merupakan salah satu home industry di bidang tekstil dengan produk yang dihasilkan berupa kain sarung dan produk - produk sandang tekstil lainnya. X telah beroperasi sejak tahun 2008, yang berlokasi di daerah Kabupaten Bandung.

Proses produksi $\mathrm{X}$ ini dilakukan oleh internal perusahaan sendiri dengan beberapa elemen pendukung yang diproduksi oleh mitra perusahaan. Strategi produksi yang diterapkan adalah make to stock dan make to order. sebagai vendor untuk melayani permintaan dari konsumen, tentu perusahaan dituntut dapat menyelesaikan permintaan produk dari konsumen secara cepat dan tepat, dengan spesifikasi yang telah ditentukan. Kapasitas produksi yang ditetapkan untuk memproduksi kain sarung sebanyak kurang lebih 15000 pcs/bulan baik untuk stock produk di gudang (make to stock) maupun permintaan dari konsumen ( make to order). Adapun tahapan dalam proses produksi kain sarung tenun ini diantaranya, proses persiapan bahan baku, proses tenun kain, proses pelembutan kain, proses pemeriksaan kecacatan dan kelayakan produk, proses potong dan jahit dan proses finishing. Objek kajian yang difokuskan pada stasiun kerja finishing ini memberi gambaran pada proses operasi yang dilakukan oleh operator, pada stasiun ini proses dibagi menjadi empat tahap pekerjaan yang dilakukan oleh beberapa operator. Tahap satu adalah melipat kain, kedua pengecapan produk yang dengan cara pengecapan label produk dengan lem, ketiga packing dengan memasukan kain yang sudah dilipat dan label lalu dimasukan kedalam plastik dan kardus karton, keempat memasukan kardus karton ukuran satuan kedalam kardus karton ukuran besar lalu dibungkus dengan kain karung. Operator pada.stasiun kerja finishing memiliki keluhan rasa pegal pada paha, kaki, pinggang, leher, dan punggung lebih banyak dibandingkan dengan stasiun kerja yang lainnya, tetapi pekerjaan packing dilakukan diakhir proses finishing hanya 3 jam sedangkan proses finishing lainnya dilakukan selama jam kerja berlangsung sehingga sikap kerja operator pada proses lipat dan pengecapan stasiun kerja finishing mengalami resiko lebih besar. Karena proses finishing ini dilakukan secara terus menerus serta tidak adanya fasilitas penunjang yang apabila tidak diperhatikan, dalam jangka waktu yang panjang dapat menyebabkan cidera gangguan otot rangka (mosculoskeletal disorder) terhadap operator. Adapun tujuan yang ingin dicapai dari penelitian yang merujuk pada permasalahan yang telah diuraikan di atas yaitu sebagai berikut:

1. Mengidentifikasi keluhan yang dirasakan operator stasiun kerja finishing pada saat melakukan pekerjaan.

2. Mengetahui risiko kerja operator stasiun kerja finishing.

3. Membuat rancangan fasilitas kerja yang ergonomis untuk operator stasiun kerja finishing.

\section{B. Landasan Teori}

\section{Ergonomi}

Ergonomi merupakan suatu ilmu, seni dan teknologi yang berupaya untuk menyerasikan alat, cara dan lingkungan kerja terhadap kemampuan, kebolehan dan segala keterbatasan manusia, sehingga manusia dapat berkarya secara optimal tanpa pengaruh buruk dari pekerjaannya. Dari sudut pandang ergnomi, antara tuntutan tugas dengan kapasitas kerja harus selalu dalam garis keseimbangan sehingga dicapai perfomansi kerja yang tinggi dalam kata lain, tuntutan tugas pekerja tidak boleh lebih rendah (underload) dan juga tidak boleh terlalu berlebihan (overload). (Tarwaka .2008, h. 7-8)

Pertimbangan - pertimbangan dalam ergonomi yang berkaitan dengan postur kerja dapat membantu mendapatkan postur kerja yang nyaman bagi pekerja. Postur kerja berdiri, duduk, maupun angkut. Beberapa jenis pekerjaan akan memerlukan postur kerja tertentu yang terkadang tidak menyenangkan. Kondisi kerja seperti ini memaksa pekerja selalu berada pada postur kerja yang tidak alami dan berlangsung dalam jangka waktu yang lama. Hal ini akan mengakibatkan pekerja cepat lelah, adanya keluhan sakit pada bagian tubuh, cacat produk bahkan cacat tubuh (Sutrisno, 2012).

\section{Quick Exposure Checklist}

Quick Exposure Checklist merupakan salah satu metode pengukuran beban postur yang diperkenalkan oleh Li dan Buckle, 1999. Metode ini menilai gangguan resiko yang terjadi pada bagian belakang punggung, bahu/lengan, pergelangan tangan, dan leher. QEC membantu untuk mencegah terjadinya WMSDs seperti gerak repetitive, gaya tekan, postur yang salah, dan durasi 
kerja (Stanton dkk, 2005). Quick Exposure Checklist digunakan untuk mengetahui resiko cedera pada otot rangkai/ sistem mosquletal (mosquletasl disorders) yang menitik beratkan pada bagian tubuh atas yakni punggung, leher, bahu dan pergelangan tangan (Yustina, 2016). tujuan penggunaan metode QEC yaitu:

1. menilai perubahan paparan pada tubuh yang beresiko terjadinya muskuloskeletal sebelum dan sesudah intervensi ergonomi

2. melibatkan pengamat dan juga pekerja dalam melakukan penilaian dan mengidentifikasi kemungkinan untuk perubahan pada sistem kerja;

3. membandingkan paparan resiko cedera diantara dua orang atau lebih yang melakukan pekerjaan yang sama, atau diantara orang-orang yang melakukan pekerjaan yang berbeda.

4. meningkatkan kesadaran diantara para manajer, engineer, desainer, praktisi keselamatan dan kesehatan kerja dan para operator mengenai faktor resiko musculoskeletal pada stasiun kerja.

Tahap Penggunaan Metode $Q E C$

Tahap penilaian menggunakan metode QEC terdapat beberapa langkah yang harus dilakukan, Langkah-langkah dalam penggunaan metode QEC dijelaskan ke dalam beberapa tahap yakni sebagai berikut:

1. Tahap pengisian lembar observasi oleh pengamat: Tahap pengisian lembar pengamatan yang diisi oleh pengamat adalah landasan dalam penilaian terhadap operator sebagai objek pengamatan. Berikut adalah lembar observasi yang harus diisi oleh pengamat ini dapat dilihat

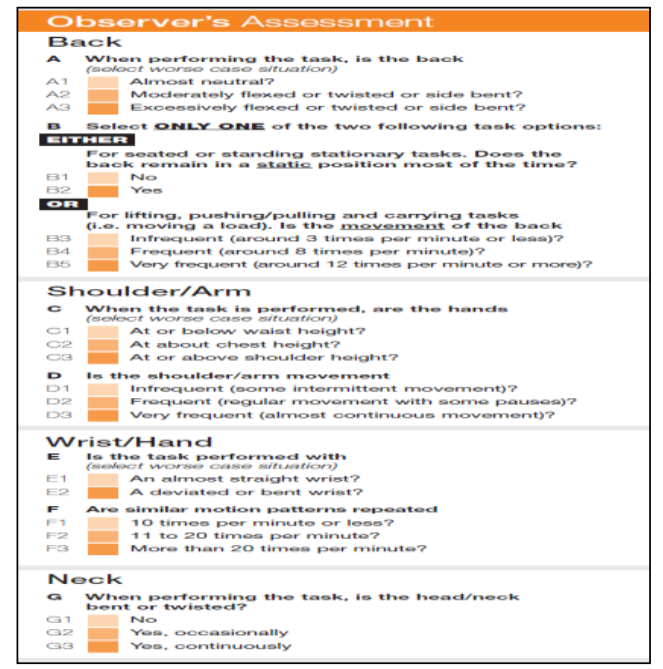

Gambar 1. Tahap pengisian lembar observasi oleh pengamat

2. Tahap pengisian lembar observasi oleh operator: Tahap pengisian lembar observasi yang diisi oleh operator merupakan landasan dalam penilaian dari operator secara langsung. 


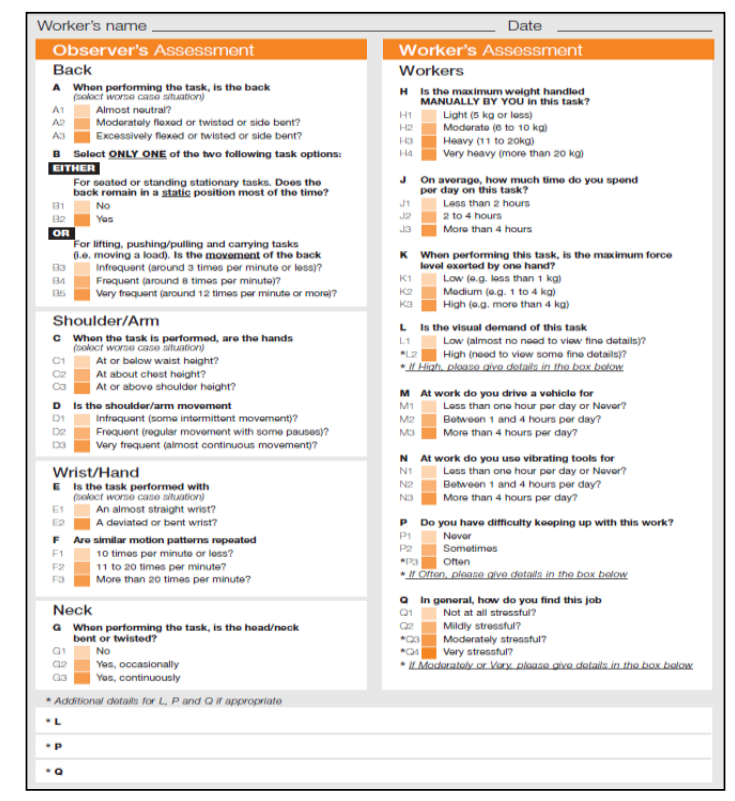

Gambar 2. Tahap pengisian lembar observasi oleh operator

\section{Antropometri}

Antropometri berasal dari "anthro" yang berarti manusia dan "metri" yang berarti ukuran. Antropometri adalah satu kumpulan data numerik yang berhubungan dengan karakteritik fisik ukuran tubuh manusia, bentuk, dan kekuatan serta penerapan dari data tersebut untuk penanganan masalah desain (Nurmianto, 2008). Antropometri dibagi ke dalam dua bagian, yaitu (Nurmianto, 2008): hal

Data antropometri yang berhasil diperoleh akan diaplikasikan secara luas antara lain dalam

1. Perancangan areal kerja (work station, interior mobil, dll)

2. Perancangan peralatan kerja seperti mesin, equipment, perkakas (tools) dan sebagainya.

3. Perancangan produk konsumtif seperti pakaian, kursi, meja komputer dan sebagainya.

4. Perancangan lingkungan kerja fisik.

Prosesdur sistematis perancangan berdasarkan antropometri, yang terdiri dari sepuluh langkah berikut (Hardianto, 2014):

1. Tentukan pupolasi pengguna yang akan menggunakan objek rancangan.

2. Tentukan dimensi tubuh yang terkait dengan objek rancangan.

3. Lihat basis data antropometri yang tersedia. Evaluasi apakah data tersebut dapat langsung digunakan untuk perancangan atau tidak.

4. Lakukan pengukuran sendiri jika basis data tidak tersedia.

5. Tentukan persentase jumlah populasi yang akan diakomodasi.

6. Tentukan pendekatan perancangan yang akan digunakan

7. Tentukan nilai ukuran untuk setiap dimensi yang sudah ditetapkan pada langkah ke-2.

8. Tambahkan besaran kelonggaran.

9. Jika memungkinkan, visualisasikan rancangan (misalnya dengan bantuan komputer).

10. Evaluasi hasil rancangan. 


\section{Hasil Penelitian dan Pembahasan}

\section{Identifikasi resiko kerja}

Dalam tahap identifikasi dengan menggunakan metode Quick exposure checklist tahapan yang akan dilakukan guna menghasilkan identifikasi yang akuran antara lain:

1. Rekapitulasi hasil pengolahan skor exposure.

Tabel 1. Rekapituasi hasil pengolahan skor

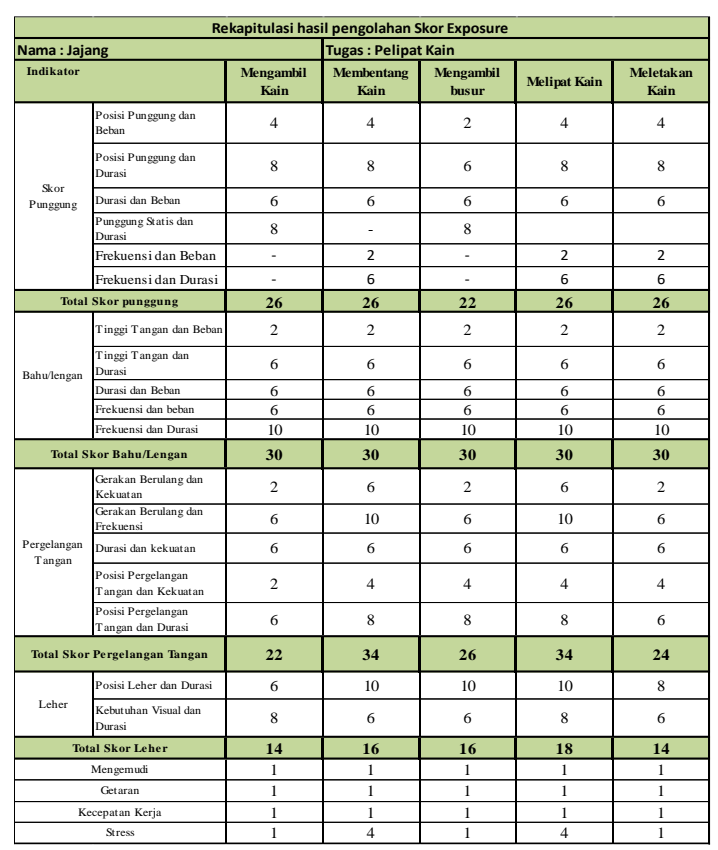

2. Menentukan level skor exposure

Tabel 2. Level Skor exposure

\begin{tabular}{|l|c|c|c|c|c|}
\hline \multicolumn{5}{|c|}{ Level Eksposur Operator 1 (Pelipat Kain) } \\
\hline \multicolumn{1}{|c|}{ Indikator } & $\begin{array}{c}\text { Mengambil } \\
\text { Kain }\end{array}$ & $\begin{array}{c}\text { Membentang } \\
\text { Kain }\end{array}$ & $\begin{array}{c}\text { Mengambil } \\
\text { busur }\end{array}$ & $\begin{array}{c}\text { Melipat } \\
\text { Kain }\end{array}$ & $\begin{array}{c}\text { Meletakan } \\
\text { Kain }\end{array}$ \\
\hline Skor Punggung & 26 & 26 & 22 & 26 & 26 \\
\hline $\begin{array}{l}\text { Level } \\
\text { Eksposur }\end{array}$ & Tinggi & Tinggi & Sedang & Tinggi & Tinggi \\
\hline $\begin{array}{l}\text { Skor Bahu / } \\
\text { Lengan }\end{array}$ & 30 & 30 & 30 & 30 & 30 \\
\hline $\begin{array}{l}\text { Level } \\
\text { Eksposur }\end{array}$ & Sedang & Sedang & Sedang & Sedang & Sedang \\
\hline $\begin{array}{l}\text { Skor } \\
\text { Pergelangan } \\
\text { Tangan }\end{array}$ & 22 & 34 & 26 & 34 & 24 \\
\hline $\begin{array}{l}\text { Level } \\
\text { Eksposur }\end{array}$ & Sedang & Tinggi & Sedang & Tinggi & Sedang \\
\hline $\begin{array}{l}\text { Skor Leher } \\
\text { Level } \\
\text { Eksposur }\end{array}$ & 14 & 16 & 16 & 18 & 14 \\
\hline
\end{tabular}

3. Menghitung total skor exposure dan penentuan action level.

Xmax merupakan bilangan konstan untuk setiap jenis pekerjaan tertentu skor maksimal: 
$(\mathrm{X} \max =162)$ diberikan ketika tubuh dalam keadaan posisi tubuh statis, duduk atau berdiri.

( $\mathrm{X} \max =176$ ) diberikan ketika pekerja melakukan penanganan manual seperti mengangkat, mendorong, menarik dan membawa beban.

Berikut perhitungan level eksposur untuk operator lipat kain, yaitu:

- Mengambil Kain

$E=\frac{(26+30+22+14)}{176} \times 100 \%$

$E=\frac{92}{176} \times 100 \%$

$E=52.36 \% \approx 52$

- Membentang Kain

$E=\frac{(26+30+34+16)}{176} \times 100 \%$

$E=\frac{106}{176} \times 100 \%$

$E=60.21 \% \approx 60$

- Mengambil Busur

$E=\frac{(22+30+26+16)}{162} \times 100 \%$

$E=\frac{94}{162} \times 100 \%$

$E=58.04 \% \approx 58$

- Melipat Kain

$E=\frac{(26+30+34+18)}{162} \times 100 \%$

$E=\frac{108}{162} \times 100 \%$

$E=61.40 \% \approx 61$

- Meletakan Kain

$E=\frac{(26+30+24+14)}{176} \times 100 \%$

$E=\frac{110}{176} \times 100 \%$

$E=53.42 \% \approx 53$ 
Tabel 3. Total skor akhir dan action level

\begin{tabular}{|l|c|c|c|c|c|}
\hline \multicolumn{5}{|c|}{ Total Skor Akhir Eksposur dan tindakan pada Operator 1 ( Pelipat Kain) } \\
\hline Elemen Kerja & $\begin{array}{c}\text { Total Skor } \\
\text { Eksposur }\end{array}$ & Skor & $\begin{array}{c}\text { Persentase } \\
\text { (\%) }\end{array}$ & $\begin{array}{c}\text { Action } \\
\text { Level }\end{array}$ & Tindakan \\
\hline $\begin{array}{l}\text { Mengambil } \\
\text { Kain }\end{array}$ & 92 & 0,523 & $52 \%$ & 3 & $\begin{array}{c}\text { Tindakan } \\
\text { dalam waktu } \\
\text { dekat }\end{array}$ \\
\hline $\begin{array}{l}\text { Membentang } \\
\text { Kain }\end{array}$ & 106 & 0,602 & $60 \%$ & 3 & $\begin{array}{c}\text { Tindakan } \\
\text { dalam waktu } \\
\text { dekat }\end{array}$ \\
\hline $\begin{array}{l}\text { Mengambil } \\
\text { Busur }\end{array}$ & 94 & 0,580 & $58 \%$ & 3 & $\begin{array}{c}\text { Tindakan } \\
\text { dalam waktu } \\
\text { dekat }\end{array}$ \\
\hline Melipat Kain & 108 & 0,614 & $61 \%$ & 3 & $\begin{array}{c}\text { Tindakan } \\
\text { dalam waktu } \\
\text { dekat }\end{array}$ \\
\hline $\begin{array}{l}\text { Meletakan } \\
\text { Kain }\end{array}$ & 94 & 0,534 & $53 \%$ & 3 & $\begin{array}{c}\text { Tindakan } \\
\text { dalam waktu } \\
\text { dekat }\end{array}$ \\
\hline
\end{tabular}

\section{Usulan rancangan fasilitas kerja}

Berdasarkan hasil dari identifikasi perhitungan identifikasi resiko kerja yang telah dilakukan pada stasiun kerja finishing maka akan diusulkan rancangan fasilitas kerja penunjang yang ergonomis guna memberikan kenyamanan dan keamanan bagi operator yang bekerja. Perancangan fasilitas yang akan dirancang merupakan fasilitas yang nantinya dapat menunjang kinerja distasiun kerja finishing. Kondisi eksisting stasiun kerja finishing yang belum ditopang dengan fasilitas kerja yang layak. Perancangan yang akan dilakukan adalah dengan membuat rancangan sebagai infografis visualisasi dengan menyesuaikan geometrik ukuran pada ukuran fasilitas kerja dari hasil yang diperoleh pada proses pengolahan data pada segmen antropometri. Rancangan fasilitas kerja yang digunakan untuk stasiun kerja finishing dengan menggunakan Catia V5 dan Autocad yang ditunjukkan pada Gambar berikut:

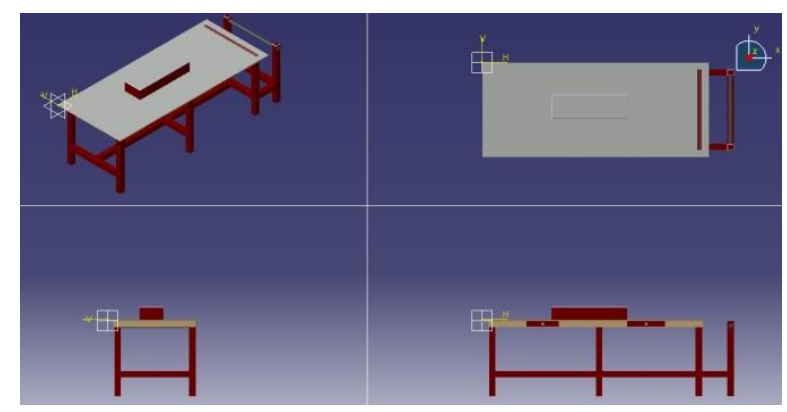

Gambar 3. Rancangan fasilitas kerja finishing 3D 


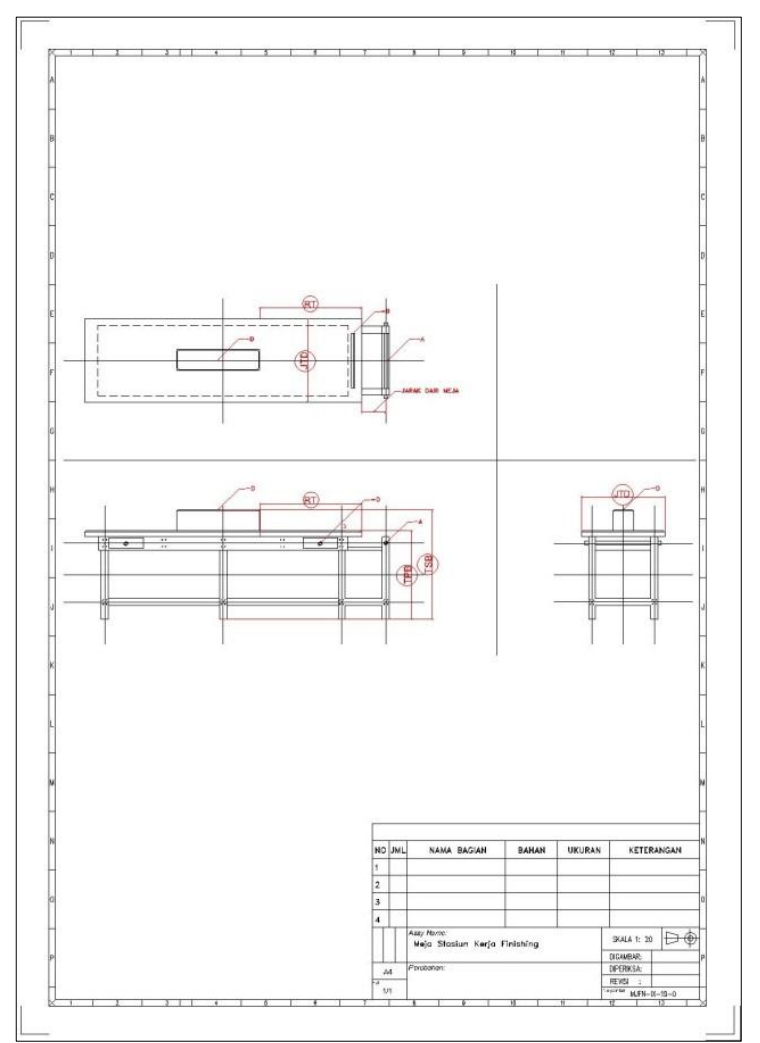

Gambar 4. Rancangan fasilitas kerja finishing 2D

\section{Penentuan dimensi meja rancangan}

Penentuan dimensi tubuh yang akan digunakan pada perancangan fasilitas kerja ini ditujukan untuk mengetahui dimensi dimensi tubuh ataupun meja yang dibutuhkan dalam proses perancangan fasilitas kerja tersebut, penentuan dimensi disertai dengan pemilihan persentil dalam standar perancangan fasilitas tersebut 
Tabel 4. Tabel dimensi rancangan

\begin{tabular}{|c|c|c|c|c|}
\hline $\begin{array}{c}\text { Bagian } \\
\text { fasilitas kerja }\end{array}$ & $\begin{array}{c}\text { Dimensi fasilitas } \\
\text { kerja }\end{array}$ & $\begin{array}{c}\text { Acuan Dimensi } \\
\text { Rancangan } \\
\end{array}$ & \begin{tabular}{|c}
$\begin{array}{c}\text { Persentil yang } \\
\text { dipilih }\end{array}$ \\
\end{tabular} & Alasan \\
\hline \multirow{3}{*}{ Meja } & Panjang meja & $\mid$ Rentang Tangan(RT) & 95 & $\begin{array}{l}\text { Agar setiap operator dengan } \\
\text { ukuran rentang tangan besar } \\
\text { dapat nyaman menggunakan } \\
\text { fasilitas meja, serta dapat }\end{array}$ \\
\hline & Lebar meja & $\begin{array}{c}\text { Jangkauan Tangan } \\
\text { Kedepan (JTD) }\end{array}$ & 50 & $\begin{array}{l}\text { Agar meja apat digunakan olet } \\
\text { operator dengan postur kecil } \\
\text { hingga besar, sehingga dapat } \\
\text { menjangkau ujung meja }\end{array}$ \\
\hline & Tinggi meja & $\begin{array}{l}\text { Tinggi Pinggul } \\
\text { Berdiri (TPB) }\end{array}$ & 50 & $\begin{array}{l}\text { Agar seluruh populasi } \\
\text { penggunan dapat } \\
\text { menggunakan fasilitas meja } \\
\text { dengan nyaman dan aman } \\
\text { dengan posisi punggung }\end{array}$ \\
\hline \multirow{4}{*}{ Laci } & Peganggan laci & \multirow{4}{*}{$\begin{array}{l}\text { Menyesuaikan } \\
\text { geometrik desain } \\
\text { ukuran meja }\end{array}$} & - & - \\
\hline & Panjang laci & & - & - \\
\hline & Lebar laci & & - & - \\
\hline & Tinggi laci & & - & - \\
\hline \multirow{3}{*}{$\begin{array}{c}\text { Hanger tempat } \\
\text { bahan untuk } \\
\text { dilipat }\end{array}$} & $\begin{array}{l}\text { Jarak tempat } \\
\text { penyimpanan } \\
\text { bahan }\end{array}$ & $\begin{array}{c}\text { Menyesuaikan } \\
\text { geometrik ukuran } \\
\text { meja }\end{array}$ & - & $\begin{array}{c}\text { agar jangkauan jarak hanger } \\
\text { tetap nyaman oleh operator } \\
\text { lipat yang berpostur kecil }\end{array}$ \\
\hline & $\begin{array}{c}\text { Lebar tempat } \\
\text { penyimpanan } \\
\text { bahan untuk } \\
\text { dilipat }\end{array}$ & $\begin{array}{c}\text { Menyesuaikan } \\
\text { geometrik ukuran } \\
\text { meja }\end{array}$ & - & - \\
\hline & $\begin{array}{l}\text { tinggi tempat } \\
\text { bahan untuk } \\
\text { dilipat }\end{array}$ & $\begin{array}{l}\text { Tinggi Pinggul } \\
\text { Berdiri }\end{array}$ & 95 & $\begin{array}{l}\text { agar jarak berbanding tinggi } \\
\text { hanger bisa menyesuaikan } \\
\text { dengan jangkauan operator } \\
\text { lipat }\end{array}$ \\
\hline \multirow{3}{*}{$\begin{array}{c}\text { Dock tempat } \\
\text { produk } \\
\text { sementara }\end{array}$} & tinggi dock & Tinggi Siku Berdiri & 5 & $\begin{array}{c}\text { agar operator pengecap dan } \\
\text { packing dengan postur kecil } \\
\text { mudah dalam menata produk } \\
\text { saat bekerja } \\
\end{array}$ \\
\hline & panjang dock & $\begin{array}{c}\text { Menyesuaikan } \\
\text { geometrik ukuran } \\
\text { meja }\end{array}$ & - & \\
\hline & lebar dock & $\begin{array}{l}\text { menyesuaikan } \\
\text { lebar produk }\end{array}$ & - & \\
\hline
\end{tabular}

\section{Penentuan ukuran rancangan fasilitas kerja meja pada perhitungan antropometri.}

Pengukuran dimensi tubuh dilakukan secara langsung terhadap seluruh pekerja yang berada di stsiun kerja finishing dengan jumlah 4 orang pekerja masing masing dengan 30 data bilangan random dari setiap dimensi yang dipilih. Pengukuran dilakukan pada beberapa dimensi tubuh yang dibutuhkan yaitu Rentang Tangan (RT),Jangkuan Tangan Kedepan (JTD), dan Tinggi Pinggul Berdiri. Berikut adalah hasil perhitungan data antropometri untuk perancangan :

1. Uji keseragaman data

Tabel 5. Rekapitulasi uji keseragaman data

\begin{tabular}{|c|c|c|c|c|c|c|}
\hline No & $\begin{array}{c}\text { Dimensi } \\
\text { Tubuh }\end{array}$ & $\mathrm{X}$ bar & $\begin{array}{c}\text { Standar } \\
\text { Deviasi }\end{array}$ & BKA & BKB & Keterangan \\
\hline 1 & RT & 163,23 & 1.63 & 166,43 & 160,03 & Seragam \\
\hline 2 & JTD & 53,6 & 2,44 & 58,38 & 48,81 & Seragam \\
\hline 3 & TPB & 85,66 & 1,78 & 89,17 & 82,16 & Seragam \\
\hline 4 & TSB & 106,90 & 1,54 & 109,92 & $\begin{array}{c}103, \\
88\end{array}$ & Seragam \\
\hline
\end{tabular}


2. Uji kecukupan data

Tabel 6. Rekapitulasi uji kecukupan data

\begin{tabular}{|c|c|c|c|c|}
\hline No & $\begin{array}{c}\text { Dimensi } \\
\text { Tubuh }\end{array}$ & $\mathbf{N}$ & $\boldsymbol{N}^{\prime}$ & Keterangan \\
\hline 1 & RT & 30 & 0,14 & Cukup \\
\hline 2 & JTD & 30 & 3,09 & Cukup \\
\hline 3 & TPB & 30 & 0,65 & Cukup \\
\hline 4 & TSB & 30 & 2,35 & Cukup \\
\hline
\end{tabular}

3. Uji kenormalan data

Tabel 7. Rekepitulasi uji kenormalan data

\begin{tabular}{|c|c|c|c|c|}
\hline No & $\begin{array}{c}\text { Dimensi } \\
\text { Tubuh }\end{array}$ & X2 tabel & $\begin{array}{c}\text { X2 } \\
\text { hitung }\end{array}$ & Kesimpulan \\
\hline 1 & RT & 7,814 & 28,08 & $\begin{array}{c}\text { Berdistribusi } \\
\text { normal }\end{array}$ \\
\hline 2 & JTD & 7,814 & 17,16 & $\begin{array}{c}\text { Berdistribusi } \\
\text { normal }\end{array}$ \\
\hline 3 & TPB & 7,814 & 10,54 & $\begin{array}{c}\text { Berdistribusi } \\
\text { normal }\end{array}$ \\
\hline 4 & TSB & 7,814 & 17,47 & $\begin{array}{c}\text { Berdistribusi } \\
\text { normal }\end{array}$ \\
\hline
\end{tabular}


4. Penentuan dimensi rancangan dan toleransi ukuran

Tabel 8. Penentuan dimensi akhir rancangan fasilitas

\begin{tabular}{|c|c|c|c|c|c|}
\hline \begin{tabular}{|c|}
$\begin{array}{c}\text { Bagian fasilitas } \\
\text { kerja }\end{array}$ \\
\end{tabular} & Dimensi fasilitas kerja & Acuan Dimensi Rancangan & Ukuran (cm) & $\begin{array}{c}\text { Tolerans } \\
(\mathrm{cm})\end{array}$ & \begin{tabular}{|c|} 
Ukuran \\
mutlak $(\mathrm{cm})$
\end{tabular} \\
\hline \multirow{3}{*}{ Meja } & Panjang meja & Rentang Tangan(RT) & $164,23 \times 3$ & 3 & 495 \\
\hline & Lebar njeja & $\mid \begin{array}{l}\text { Jangkauan Tangan Kedepan } \\
\text { (JTD) }\end{array}$ & $53,6 \times 2$ & 3 & 110 \\
\hline & Tinggi inja & Tinggi Pinggul Berdiri (TPB) & 85,67 & 4 & 90 \\
\hline \multirow{4}{*}{ Laci } & Peganggan haci & \multirow{4}{*}{$\begin{array}{c}\text { Menyesuaikan geonertik } \\
\text { desain ukuran nejia }\end{array}$} & 3 & - & 3 \\
\hline & Panjang haci & & 40 & - & 40 \\
\hline & Lebar aci & & 50 & - & 50 \\
\hline & Tinggi laci & & 15 & - & 15 \\
\hline \multirow{3}{*}{\begin{tabular}{|l} 
Hanger e empat \\
bahan unutuk \\
dilipat
\end{tabular}} & $\begin{array}{c}\text { Jarak kempat } \\
\text { penyyinpanan bahan }\end{array}$ & $\begin{array}{c}\text { Menyessuakan geonentrik } \\
\text { ukuran neja }\end{array}$ & 30 & - & 30 \\
\hline & $\begin{array}{c}\text { Lebar tenpat } \\
\text { penyyimanan bahan } \\
\text { untuk dilipatat }\end{array}$ & $\begin{array}{c}\text { Menyesuakan geomertik } \\
\text { ukuran neja }\end{array}$ & $53,6 \times 2$ & 3 & 110 \\
\hline & $\begin{array}{l}\text { tinggi tenpat bahan } \\
\text { untuk dilipat }\end{array}$ & Tinggi Pinggul Berdiri & 85,67 & 4 & 90 \\
\hline \multirow{3}{*}{\begin{tabular}{|c} 
Dock tempat \\
produk \\
sementara
\end{tabular}} & tinggi dock & Tinggi Siku Berdiri & 104,6 & 10 & 115 \\
\hline & panjang dock & $\begin{array}{c}\text { Menyesuakanan geometrik } \\
\text { ukuran neja }\end{array}$ & 150 & . & 150 \\
\hline & lebar dock & menyesuaikan lebar produk & 20 & - & 20 \\
\hline
\end{tabular}




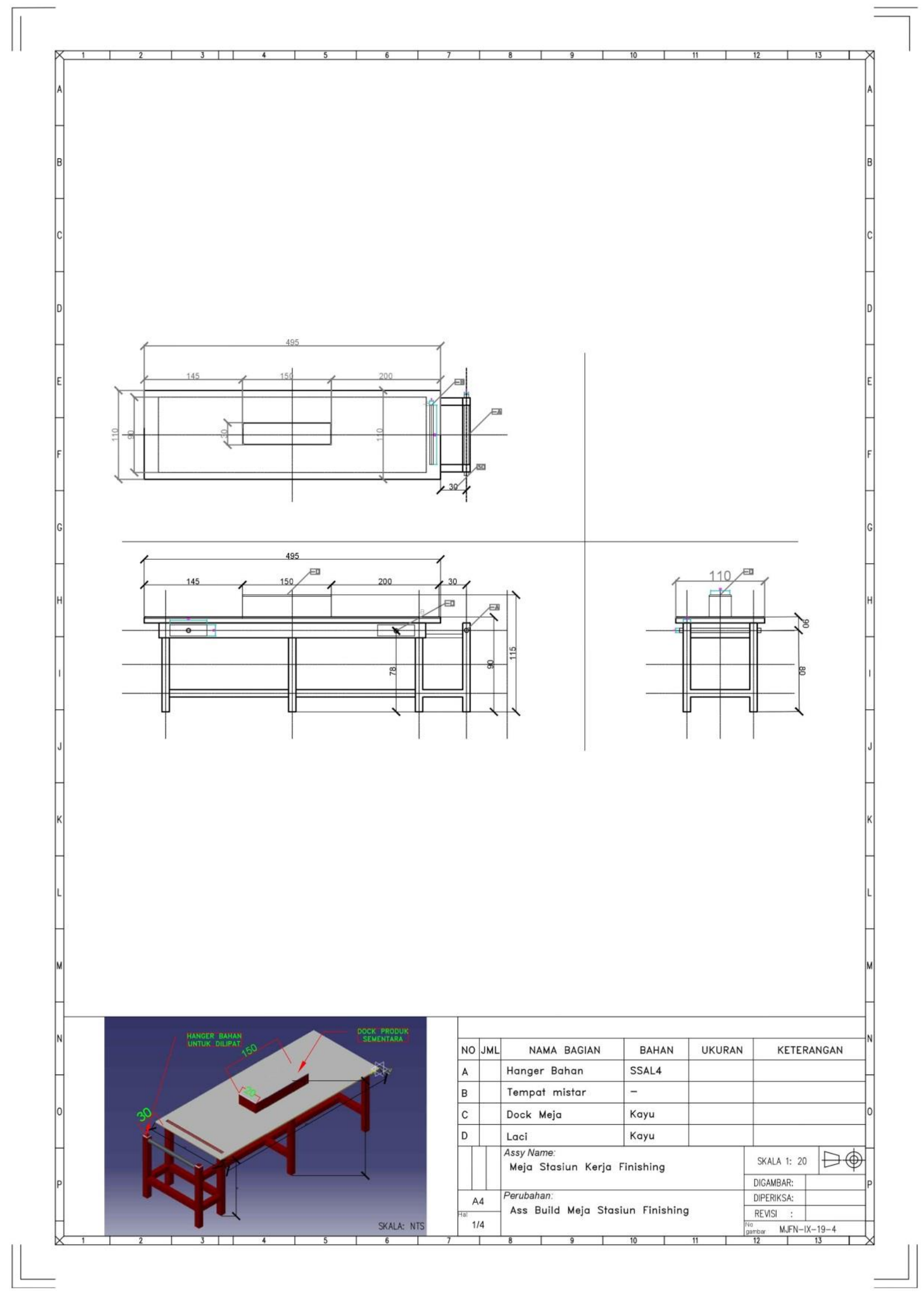

Gambar 4. Visualisasi rancangan fasilitas kerja stasiun finishing 


\section{Kesimpulan}

Berdasarkan hasil penelitian, pengolahan data serta analisis yang telah dilakukan sejauh ini, maka diperoleh kesimpulan yaitu sebagai berikut :

1. Operator stasiun kerja finishing bekerja tanpa fasilitas kerja penunjang aktifitas produksi, operator bekerja dengan posisi duduk/jongkok, duduk dengan kaki terlipat dilantai dengan sikap kerja punggung yang membungkuk dan leher yang menunduk. Dari hasil observasi lapangan dan wawancara terhadap objek sumber penelitian, operator mengeluhkan terkadang mengeluhkan nyeri pada beberapa bagian tubuh. keluhan terkait dirasakan dibagian sekitar punggung atas dan bawah, leher serta kaki. Faktor tersebut dikeluhkan karena operator bekerja pada posisi tubuh dengan postur gerak terbatas dengan kurun waktu yang cukup lama. Hal ini akan berdampak pada kesehatan dan keselematan serta kinerja

2. Hasil pengukuran tingkat resiko kerja menggunakan metode Quick Exposure Checklist pada stasiun kerja finishing menunjukan level 3 (skala 5) dengan level tindakan harus dilakukan tindakan penanggulangan dalam waktu dekat. Faktor yang mempengaruhi tingginya tingkat resiko yaitu penilaian dibagian punggung yang membungkuk dalam jangka waktu yang lama, leher atau kepala yang menunduk secara terus menerus dan pergelangan tangan yang selalu tertekuk. Sikap kerja yang dipaksakan untuk tetap bekerja pada posisi ruang gerak terbatas bagi operator akan berdampak dalam jangka waktu ataupun dekat. Dengan hasil pengukuran yang menunjukan level yang tinggi, maka harus dilakukan perbaikan posisi kerja dalam waktu dekat untuk menghindari cidera yang lebih serius terhadap operator.

3. Langkah tindakan dalam menangani besarnya resiko kerja yang didapat dari penelitian yang telah dilakukan pada stasiun kerja ini adalah dengan melakukan perancangan fasilitas kerja pada stasiun finishing. Hal ini dilakukan karena kondisi eksisting stasiun kerja yang belum ditopang dengan fasilitas kerja yang baik, maka usulan tindakan pada permasalahan ini dengan melakukan perancangan fasilitas sebagai usulan alternatif dalam menanggulangi permasalahan pada stasiun kerja finishing. Membuat rancangan fasilitas kerja yang ergonomis untuk operator stasiun kerja finishing diharapkan dapat meminimasi keluhan hingga resiko kerja operator, serta senantiasa nyaman dan aman saat melakukan aktifitas pekerjaan.

\section{E. Saran}

Setelah melakukan penelitian ini, terdapat beberapa saran terhadap perusahaan dan penelitian selanjutnya, diantaranya:

1. Memperhatikan seluruh posisi dan sikap kerja operator pada seluruh stasiun kerja untuk menghindari cidera atau resiko yang akan diterima operator.

2. Meningkatkan kenyamanan dan kesehatan lingkungan kerja.

3. Memberikan penyuluhan kepada operator apabila terdapat operator mengalami cidera untuk melakukan pemeriksaan ke dokter atau terapis.

4. Memberikan rekomendasi - rekomendasi tentang perancangan fasilitas bagi operator kerja yang baik untuk kenyamanan saat bekerja.

5. Penelitian selanjutnya diharapkan dapat memperbaiki lingkungan fisik kerja untuk operator produksi dan finsihing, selain itu juga untuk memperbaiki tata letak penyimpanan benang di gudang yang cukup beresiko pada saat menyimpan dan akan mengambil.

\section{Daftar Pustaka}

[1] David G., W. V. (2005). Further development of the usability and validity of the Quick Exposure Check (QEC). Norwich: Health \& Safety Executive. Dalam H. d. Iridiastadi, Ergonomi Suatu Pengantar. Bandung: PT Remaja Rosdakarya.

[2] Hardianto, I. (2014). Ergonomi Suatu Penerapan. Bandung: PT. Remaja Rosdakarya.

[3] Nurmianto, E. (2008). Ergonomi Konsep Dasar dan Aplikasinya. Surabaya: PT Guna Widya.

[4] Santoso, G. (2004). Ergonomi Manusia, Peralatan, dan Lingkungan. Jakarta: PT. Prestasi 
Pusaka.

[5] Stanton, e. a. (2005). Handbook of Human Factors And Ergonomics Methods. CRC Press. USA.

[6] Sutrisno, A. d. (2012). Analisis Ergonomi Terhadap Perancangan Fasilitas Kerja. Jurnal Politeknik Negeri Jember.

[7] Tarwaka, B. S. (2008). Ergonomi Untuk Keselamatan, Kesehatan Kerja, dan Produktivitas.

[8] Wignjosoebroto. (2008). Ergonomi, Studi Gerak, dan Waktu Teknik Analisis untuk Peningkatan Produktivitas Kerja. Surabaya: PT Guna Widya.

[9] Yustina, W. (2016). Analisis resiko postur kerja dengan metode quick exposure checklist dan pendekatan fisiologis pada proses pembuatan tahu. Universitas Muhammadiyah Surakarta. 